\title{
ACUTE AND CHRONIC TOXICITY STUDIES OF THE WATER EXTRACT FROM DRIED FRUITS OF TERMINALIA BELLERICA (GAERTN.) ROXB. IN SPARGUE-DAWLEY RATS
}

\section{Seewaboon Sireeratawong ${ }^{1 *}$, Kanjana Jaijoy ${ }^{2}$, Watcharin Panunto ${ }^{3}$, Urarat Nanna ${ }^{1}$, Nirush Lertprasertsuke $^{4}$, Noppamas Soonthornchareonnon ${ }^{5}$}

${ }^{1}$ Division of Pharmacology, Department of Preclinical Science, Faculty of Medicine, Thammasat University, Pathum Thani 12120, Thailand. ${ }^{2}$ Department of Pharmacology, Faculty of Medicine, Chiang Mai University, Chiang Mai 50200, Thailand. ${ }^{3}$ Department of Preclinical Science, Faculty of Medicine, Thammasat University, Pathum Thani 12120, Thailand. ${ }^{4}$ Department of Pathology,

Faculty of Medicine, Chiang Mai University, Chiang Mai 50200, Thailand.

${ }^{5}$ Department of Pharmacognosy, Faculty of Pharmacy, Mahidol University, Bangkok 10400, Thailand. Sireeratawong S:

*E-mail: seewaboon@gmail.com

\begin{abstract}
Acute and chronic toxicities of the water extract from the dried fruits of Terminalia bellerica (Gaertn.) Roxb. were assessed in both female and male rats. For the study of acute toxicity, a single oral administration of the water extract at a dose of 5,000 mg/kg body weight (10 female, 10 male) was performed and the results showed no signs of toxicity such as general behavior changes, morbidity, mortality, changes on gross appearance or histopathological changes of the internal organs of rats. The study of chronic toxicity was determined by oral feeding both female and male rats (10 female, 10 male) daily with the test substance at the dose of 300,600 and $1,200 \mathrm{mg} / \mathrm{kg}$ body weight continuously for 270 days. The examinations of signs of toxicity showed no abnormalities in the test groups compared to the controls. In addition, these rats were analyzed for final body and organ weights, necropsy, as well as hematological, blood chemical and histopathological parameters. Taken together, the water extract from the dried fruits of $T$. bellerica did not cause acute or chronic toxicities in either female or male rats.
\end{abstract}

Keywords: Terminalia bellerica; acute toxicity; chronic toxicity

\section{Introduction}

Terminalia bellerica (Gaertn.) Roxb. is an indigenous plant in Southeast Asia and Thailand. It is a plant in the family Combretaceae and commonly known as "Sa Maw Phi Phek" in Thai name (Smitinand, 2001). T. bellerica has been extensively used in Thai traditional medicine for laxative, carminative, astringent, expectorant and tonic (Department of Medical Sciences, Ministry of Public Health 2000). The pharmacological activities of T. bellerica have been shown to display a wide spectrum such as antibacterial (Elizabeth 2005; Ahmad et al., 1998), antifungal (Valsaraj et al., 1997), antioxidant (Bajpai et al., 2005), and anti-HIV-1 reverse transcriptase (el-Mekkawy et al., 1995). Only limited toxicity data of these plants have been reported. The acute toxicity study of the alcoholic extract from fruits of $T$. bellerica showed no toxic effects in mice (Mokkhasmit et al., 1971) or rats (Thanaporn et al., 2006). In subchronic toxicity study, the 95\% ethanolic extract from its fruits in rats presented no toxic effects (Thanaporn et al., 2006). Nevertheless, acute and chronic toxicity studies of the water extract has not yet been studied. Consequently, the aim of this study was to evaluate the acute and chronic toxicity of the water extract of $T$. bellerica in rats.

\section{Materials and methods Plant material}

The mature fruits of T. bellerica were collected during September to November from the forest of Wangnumyen district, Sakaew province, Thailand. The plant material was identified and the voucher specimen (PBM 02678) was kept at Faculty of Pharmacy, Mahidol University, Bangkok, Thailand.

\section{Preparation of $T$. bellerica water extract (TB extract)}

The method of preparation was described. Briefly, $104 \mathrm{~kg}$ of $T$. bellerica dry fruits were boiled for 1 hour and filtered. This process was repeated 3 times. The extract is spray dried to remove trace of water. After that, TB extract was tested to control quality such as physical appearance, percentage of loss on drying, total ash, acid insoluble ash, microbial test, aflatoxin test, heavy metal, and quantity of chemical compounds (percentage of tannins, total carbohydrate, uronic acid, and gallic acid), according to Thai herbal pharmacopoeia. 


\section{Experimental animals}

Adult female and male Sprague-Dawley (SD) rats, 8-10 weeks old were obtained from the National Laboratory Animal Center, Nakorn Pathom, Thailand. They were housed under standard environmental conditions of temperature at 24 $\pm 1{ }^{\circ} \mathrm{C}$ under a $12 \mathrm{~h}$ dark-light cycle, and allowed free access to drinking water and standard pellet diet. Rats were deprived of food except water 16-18 hour prior the experiments. The Animal Ethics Committee of Faculty of Medicine, Thammasat University approved all experimental protocols (No. 0001/2007).

\section{Acute oral toxicity in rats}

The single dose acute oral toxicity study was evaluated following the recommendations by OECD (2001) and WHO (2000). Ten rats per sex were administrated a single oral dose of TB extract at a dose of 5,000 mg/kg while the control group received water vehicle. Body weight, signs of toxicity and mortality were observed after the administration at the first, second, fourth and sixth hour and once daily for 14 days. On the $15^{\text {th }}$ day, all rats were sacrificed for necropsy examination.

\section{Chronic oral toxicity in rats Experimental design}

The chronic 270-day oral toxicity study was evaluated following the advice by OECD (1981) and WHO (2000). Female and male rats were randomly divided into five groups $(\mathrm{n}=10)$ and received doses of $0,300,600 \mathrm{and} 1,200 \mathrm{mg} / \mathrm{kg}$ of TB extract at daily gavage of $1 \mathrm{ml} / \mathrm{kg}$ for 270 days while the control group received distilled water vehicle. In the satellite group, the extract at the dose of $1,200 \mathrm{mg} / \mathrm{kg}$ was given once daily to the fifth group of rats for 270 days, and kept for another 28 days post treatment. Changes in general appearance or behavior, signs of toxicity, mortality and the body weight changes were monitored daily. At the end of 270 days (satellite group 298 days), all rats were fasted overnight but with free access to water and anesthetized for blood collection from common carotid artery for hematological and chemical examination. During necropsy, the internal organs and some tissues were dissected, weighed and observed for gross lesions. All tissues were preserved in $10 \%$ neutral buffered formalin solution for pathological examination.

\section{Hematology and clinical blood chemistry examination}

Hematology analysis was performed using an automated hematology analyzer, Sysmex SF-3000. Whole blood samples were collected into CBC bottles containing $0.5 \%$ ethylenediaminetetraacetic acid (EDTA)-2K for the following parameters: red blood cells, hemoglobin concentration, hematocrit, mean corpuscular volume (MCV), mean corpuscular hemoglobin (MCH), mean corpuscular hemoglobin concentration (MCHC), platelet, white blood cells, and differential white blood cells. Serum from blood samples collected in separator tubes was measured using the COBAS INTEGRA analyzer, including glucose, blood urea nitrogen (BUN), creatinine, total protein, albumin, total and direct bilirubins, aspartate aminotransferase (AST), alanine aminotransferease (ALT), and alkaline phosphatase (ALP) analyzes.

\section{Gross and histopathological examination}

The positions, shapes, sizes and colors of the internal organs were observed. Brain, lung, heart, liver, spleen, pancreas, kidney, adrenal gland, small intestine, stomach, muscle, testes and ovaries in every group were weighed and preserved in $10 \%$ neutral buffered formalin, sectioned and stained with hematoxylin and eosin (H\&E).

\section{Statistical analysis}

Results were expressed as mean \pm standard error of mean (S.E.M.). Statistical significance was determined by oneway analysis of variance (ANOVA) and post hoc least-significant difference (LSD) test. The data obtained from acute toxicity studies were analyzed using Student's $t$-test. $P$ values less than 0.05 were considered significant.

\section{Results TB extract}

The values of quality control and quantity of chemical compounds of TB extract were remained within the normal ranges. TB extract contains $34.46 \%$ of tannins, $7.98 \%$ of gallic acid, $20 \%$ of total carbohydrate, and $5.28 \%$ of uronic acid. The water extract was not contaminated with aflatoxin, pesticide, heavy metal and microbials.

\section{Acute oral toxicity}

The toxic signs, mortalities did not occur in control rats or in female and male rats fed with 5,000 mg/kg of TB extract, and neither body weight nor internal organ weight of treated rats was significantly changed relative to that of the control group. The internal organs of treated rats such as lung, liver, kidney, spleen, adrenal grand, heart, pancreas, brain and sex organ showed no pathological abnormality relative to these organs of the control group (data not shown). Therefore, the female and male SD rat oral $\mathrm{LD}_{50}$ of TB extract was considered to be more than $5,000 \mathrm{mg} / \mathrm{kg}$. 


\section{Chronic oral toxicity}

General behavior and body weight

All of the rats fed with TB extract showed normal general behavior, respiratory pattern, cardiovascular signs, motor activities, reflexes, and normal change in skin and fur. Moreover, the female treated groups had no significant differences in their body weight and body weight gain when compared with the control groups. In the male treated group, the body weight and body weight gain showed significant decreases when compared with the control group (Figure 1).

\section{Hematology}

The female rats treated with various doses showed no significant difference when compared with the control (Table 1). The mean corpuscular volume (MCV) was significantly decreased in the male rats treated with $600 \mathrm{mg} / \mathrm{kg}$ (Table 1). The differential white blood cell count values are listed in Table 2. In female rats, a significant increase in neutrophil and a significant decrease in lymphocyte were observed in the satellite group. In male rats, a significant increase in white blood cell was observed in the treated groups with 300 and $600 \mathrm{mg} / \mathrm{kg}$. The male rats treated with $600 \mathrm{mg} / \mathrm{kg}$, lymphocyte was significantly decreased when compared with the control group.

\section{Clinical blood chemistry}

Clinical blood chemistry examination showed an increased glucose level in female rats treated with 300 and 600 $\mathrm{mg} / \mathrm{kg}$, a decrease of albumin, total bilirubin, direct bilirubin, aspartate aminotransferase (AST) and an increase of alkaline phosphatase (ALP) levels in the satellite group (Table 3). In the male rats treated with $1,200 \mathrm{mg} / \mathrm{kg}$, results showed an increase of total protein while the satellite male group had a significant decrease of blood urea nitrogen (BUN), total bilirubin, and direct bilirubin concentrations (Table 3).

\section{Internal organ weight and histopathological examination}

Rats receiving TB extract showed normal structure, size, shape, color and texture of internal organs (kidneys, livers, adrenals, sex organs, thymus, stomach, intestine, muscle, pancreas, brain and spinal cord). The organ weights of the female treated groups were no significant differences when compared with the control group (data not shown). The male treatment groups with $600 \mathrm{mg} / \mathrm{kg}$ showed a decrease in brain, lung, heart, liver, and kidney weight and a decrease in lung heart and spleen weight of male treatment groups with $1,200 \mathrm{mg} / \mathrm{kg}$. The satellite male group showed a significant increase in the kidney weight (Table 4).
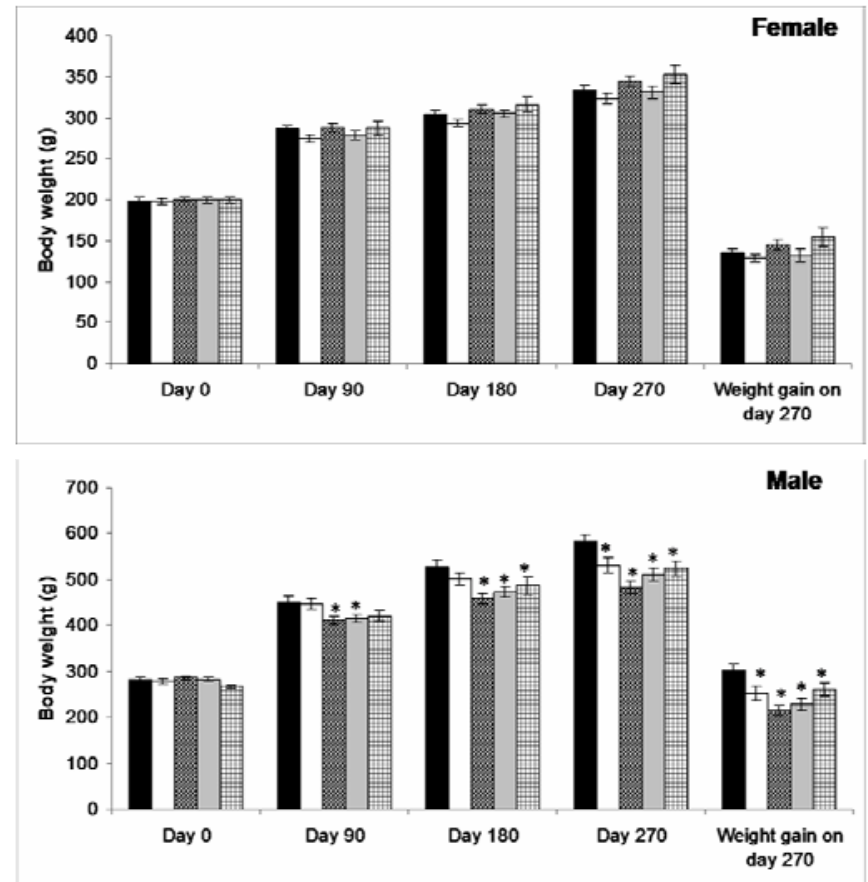

Figure 1 Body weights of rats in the chronic toxicity study of the $T$. bellerica water extract. *Significantly different from control, $\mathrm{p}<0.05$. 
Sireeratawong et al., Afr J Tradit Complement Altern Med. (2013) 10(2):223-231

Table 1: Effect of $T$. bellerica water extract on the hematological values of female and male rats in the chronic toxicity test

\begin{tabular}{|c|c|c|c|c|c|}
\hline \multirow[b]{2}{*}{ Hematological values } & \multirow[b]{2}{*}{ Control } & \multicolumn{4}{|c|}{ T. bellerica water extract } \\
\hline & & 300 mg/kg & $600 \mathrm{mg} / \mathrm{kg}$ & $1,200 \mathrm{mg} / \mathrm{kg}$ & Satellite \\
\hline \multicolumn{6}{|l|}{ Female } \\
\hline Red Blood Cell (x10\% $/ \mu \mathrm{l})$ & $7.36 \pm 0.05$ & $7.21 \pm 0.14$ & $7.43 \pm 0.04$ & $7.25 \pm 0.08$ & $7.31 \pm 0.14$ \\
\hline Hemoglobin (g/dl) & $15.40 \pm 0.10$ & $15.12 \pm 0.22$ & $15.45 \pm 0.10$ & $15.10 \pm 0.15$ & $15.07 \pm 0.26$ \\
\hline Hematocrit (\%) & $45.40 \pm 0.34$ & $44.13 \pm 0.92$ & $45.70 \pm 0.37$ & $44.30 \pm 0.40$ & $45.20 \pm 0.80$ \\
\hline MCV (fl) & $61.53 \pm 0.37$ & $61.05 \pm 0.29$ & $61.51 \pm 0.38$ & $61.18 \pm 0.30$ & $61.95 \pm 0.42$ \\
\hline MCH (pg) & $20.92 \pm 0.13$ & $20.96 \pm 0.23$ & $20.85 \pm 0.15$ & $20.85 \pm 0.09$ & $20.65 \pm 0.16$ \\
\hline MCHC (g/dl) & 34.000 .18 & $34.34 \pm 0.35$ & $33.9 \pm 0.21$ & $34.05 \pm 0.18$ & $33.90 \pm 0.57$ \\
\hline Platelet $\left(\mathrm{x} 10^{5} / \mu \mathrm{l}\right)$ & $5.47 \pm 0.17$ & $6.12 \pm 0.21$ & $5.77 \pm 0.13$ & $5.85 \pm 0.23$ & $5.84 \pm 0.56$ \\
\hline \multicolumn{6}{|l|}{ Male } \\
\hline Red Blood Cell $\left(x 10^{6} / \mu \mathrm{l}\right)$ & $8.30 \pm 0.21$ & $8.56 \pm 0.10$ & $8.67 \pm 0.10$ & $8.55 \pm 0.11$ & $8.57 \pm 0.13$ \\
\hline Hemoglobin (g/dl) & $16.05 \pm 0.23$ & $16.37 \pm 0.15$ & $16.19 \pm 0.20$ & $16.11 \pm 0.23$ & $16.14 \pm 0.21$ \\
\hline Hematocrit (\%) & $49.70 \pm 0.73$ & $51.11 \pm 0.61$ & $50.40 \pm 0.58$ & $50.20 \pm 0.80$ & $50.56 \pm 0.75$ \\
\hline MCV (fl) & $59.84 \pm 0.90$ & $59.62 \pm 0.43$ & $58.26 \pm 0.58$ & $58.67 \pm 0.47$ & $59.02 \pm 0.17$ \\
\hline MCH (pg) & $19.40 \pm 0.31$ & $19.09 \pm 0.15$ & $18.69 \pm 0.22 *$ & $18.85 \pm 0.20$ & $18.87 \pm 0.11$ \\
\hline MCHC (g/dl) & $32.43 \pm 0.19$ & $32.07 \pm 0.27$ & $32.08 \pm 0.18$ & $32.14 \pm 0.13$ & $31.94 \pm 0.20$ \\
\hline Platelet $\left(\mathrm{x} 10^{5} / \mu \mathrm{l}\right)$ & $8.04 \pm 0.22$ & $7.80 \pm 0.18$ & $7.99 \pm 0.19$ & $8.00 \pm 0.20$ & $7.51 \pm 0.32$ \\
\hline
\end{tabular}

Values are expressed as mean \pm S.E.M., $\mathrm{n}=10$.

Satellite: a group was treated with oral dose of $1,200 \mathrm{mg} / \mathrm{kg}$ body weight/day for 270 days following by no treatment for 28 days.

* Significantly different from control, $\mathrm{p}<0.05$. 
Sireeratawong et al., Afr J Tradit Complement Altern Med. (2013) 10(2):223-231

http://dx.doi.org/10.4314/ajtcam.v10i2.6

Table 2: Effect of $T$. bellerica water extract on the differential white blood cell count values of female rats in the chronic toxicity test

\begin{tabular}{|c|c|c|c|c|c|}
\hline \multirow[b]{2}{*}{ Hematological values } & \multirow[b]{2}{*}{ Control } & \multicolumn{4}{|c|}{ T. bellerica water extract } \\
\hline & & $300 \mathrm{mg} / \mathrm{kg}$ & $600 \mathrm{mg} / \mathrm{kg}$ & $1,200 \mathrm{mg} / \mathrm{kg}$ & Satellite \\
\hline \multicolumn{6}{|l|}{ Female } \\
\hline White blood cell $\left(\mathrm{x} 10^{3} / \mu \mathrm{l}\right)$ & $2.75 \pm 0.25$ & $2.41 \pm 0.19$ & $3.09 \pm 0.42$ & $3.09 \pm 0.24$ & $3.00 \pm 0.47$ \\
\hline Neutrophil (\%) & $14.50 \pm 1.20$ & $16.38 \pm 2.15$ & $18.40 \pm 2.56$ & $14.00 \pm 1.00$ & $26.00 \pm 4.13^{*}$ \\
\hline Lymphocyte (\%) & $71.41 \pm 1.66$ & $70.00 \pm 2.67$ & $66.50 \pm 3.26$ & $69.70 \pm 1.20$ & $62.50 \pm 4.43^{*}$ \\
\hline Monocyte (\%) & $9.70 \pm 0.84$ & $9.00 \pm 1.17$ & $10.80 \pm 0.65$ & $10.60 \pm 0.56$ & $8.30 \pm 0.50$ \\
\hline Eosinophil (\%) & $4.40 \pm 0.86$ & $4.63 \pm 0.98$ & $4.30 \pm 1.45$ & $5.70 \pm 0.80$ & $3.20 \pm 0.63$ \\
\hline Basophil (\%) & $0.00 \pm 0.00$ & $0.00 \pm 0.00$ & $0.00 \pm 0.00$ & $0.00 \pm 0.00$ & $0.00 \pm 0.00$ \\
\hline \multicolumn{6}{|l|}{ Male } \\
\hline White blood cell $\left(\mathrm{x} 10^{3} / \mu \mathrm{l}\right)$ & $4.31 \pm 0.55$ & $6.74 \pm 0.05^{*}$ & $5.98 \pm 0.41^{*}$ & $4.36 \pm 0.69$ & $4.22 \pm 0.23$ \\
\hline Neutrophil (\%) & $25.70 \pm 5.05$ & $28.89 \pm 3.59$ & $31.50 \pm 3.43$ & $22.90 \pm 2.25$ & $31.33 \pm 3.22$ \\
\hline Lymphocyte (\%) & $65.70 \pm 4.00$ & $59.11 \pm 3.67$ & $56.10 \pm 3.70^{*}$ & $66.00 \pm 2.42$ & $57.22 \pm 2.52$ \\
\hline Monocyte (\%) & $9.70 \pm 0.21$ & $10.00 \pm 1.38$ & $9.40 \pm 0.40$ & $8.40 \pm 0.70$ & $8.22 \pm 0.52$ \\
\hline Eosinophil (\%) & $2.20 \pm 0.20$ & $2.56 \pm 0.56$ & $3.10 \pm 0.61$ & $2.70 \pm 0.76$ & $2.67 \pm 0.50$ \\
\hline Basophil (\%) & $0.00 \pm 0.00$ & $0.00 \pm 0.00$ & $0.00 \pm 0.00$ & $0.00 \pm 0.00$ & $0.00 \pm 0.00$ \\
\hline
\end{tabular}

Basophil (\%)

Values are expressed as mean + S.E.M., $n=10$

Satellite: a group was treated with oral dose of $1,200 \mathrm{mg} / \mathrm{kg}$ body weight/day for 270 days following by no treatment for 28 days.

* Significantly different from control, $\mathrm{p}<0.05$. 
Sireeratawong et al., Afr J Tradit Complement Altern Med. (2013) 10(2):223-231

Table 3: Effect of T. bellerica water extract on blood chemical values of female and male rats in the chronic toxicity test

\begin{tabular}{|c|c|c|c|c|c|}
\hline \multirow[b]{2}{*}{ Hematological values } & \multirow[b]{2}{*}{ Control } & \multicolumn{4}{|c|}{ T. bellerica water extract } \\
\hline & & $300 \mathrm{mg} / \mathrm{kg}$ & $600 \mathrm{mg} / \mathrm{kg}$ & $1,200 \mathrm{mg} / \mathrm{kg}$ & Satellite \\
\hline \multicolumn{6}{|l|}{ Female } \\
\hline Glucose (mg/dl) & $114.60 \pm 4.16$ & $127.00 \pm 4.66^{*}$ & $125.30 \pm 1.78^{*}$ & $118.60 \pm 2.75$ & $124.20 \pm 5.01$ \\
\hline BUN (mg/dl) & $19.10 \pm 0.62$ & $18.25 \pm 3.23$ & $17.90 \pm 0.71$ & $19.10 \pm 0.82$ & $18.90 \pm 0.88$ \\
\hline Creatinine (mg/dl) & $0.42 \pm 0.02$ & $0.44 \pm 0.02$ & $0.41 \pm 0.01$ & $0.41 \pm 0.02$ & $0.41 \pm 0.02$ \\
\hline Total protein (g/dl) & $5.86 \pm 0.04$ & $5.81 \pm 0.06$ & $5.95 \pm 0.10$ & $5.82 \pm 0.08$ & $5.81 \pm 0.09$ \\
\hline Albumin (g/dl) & $3.96 \pm 0.03$ & $3.94 \pm 0.06$ & $4.02 \pm 0.07$ & $3.95 \pm 0.05$ & $3.74 \pm 0.09 *$ \\
\hline Total bilirubin (mg/dl) & $0.24 \pm 0.02$ & $0.21 \pm 0.02$ & $0.23 \pm 0.03$ & $0.26 \pm 0.02$ & $0.16 \pm 0.02 *$ \\
\hline Direct bilirubin (mg/dl) & $0.07 \pm 0.02$ & $0.06 \pm 0.02$ & $0.07 \pm 0.02$ & $0.07 \pm 0.02$ & $0.00 \pm 0.00 *$ \\
\hline AST (U/l) & $148.50 \pm 10.02$ & $131.25 \pm 11.08$ & $125.70 \pm 6.29$ & $146.70 \pm 13.66$ & $114.60 \pm 8.70^{*}$ \\
\hline $\operatorname{ALT}(\mathrm{U} / \mathrm{l})$ & $47.30 \pm 4.24$ & $40.13 \pm 3.93$ & $39.40 \pm 3.39$ & $45.00 \pm 4.41$ & $41.30 \pm 2.97$ \\
\hline ALP (U/l) & $28.30 \pm 1.06$ & $30.00 \pm 2.18$ & $31.50 \pm 2.17$ & $28.60 \pm 1.19$ & $37.10 \pm 5.21 *$ \\
\hline \multicolumn{6}{|l|}{ Male } \\
\hline Glucose (mg/dl) & $136.88 \pm 4.03$ & $130.63 \pm 4.38$ & $143.63 \pm 7.09$ & $127.78 \pm 3.05$ & $142.44 \pm 5.46$ \\
\hline BUN (mg/dl) & $20.30 \pm 0.62$ & $20.67 \pm 0.65$ & $19.30 \pm 0.67$ & $19.40 \pm 0.62$ & $18.56 \pm 0.29 *$ \\
\hline Creatinine (mg/dl) & $0.36 \pm 0.02$ & $0.37 \pm 0.02$ & $0.35 \pm 0.02$ & $0.31 \pm 0.02$ & $0.41 \pm 0.02$ \\
\hline Total protein (g/dl) & $5.95 \pm 0.08$ & $6.14 \pm 0.10$ & $6.09 \pm 0.08$ & $6.20 \pm 0.06 *$ & $6.11 \pm 0.08$ \\
\hline Albumin (g/dl) & $3.63 \pm 0.08$ & $3.66 \pm 0.07$ & $3.67 \pm 0.05$ & $3.77 \pm 0.04$ & $3.57 \pm 0.06$ \\
\hline Total bilirubin (mg/dl) & $0.19 \pm 0.01$ & $0.19 \pm 0.01$ & $0.18 \pm 0.01$ & $0.20 \pm 0.00$ & $0.11 \pm 0.01 *$ \\
\hline Direct bilirubin (mg/dl) & $0.07 \pm 0.02$ & $0.06 \pm 0.02$ & $0.08 \pm 0.01$ & $0.09 \pm 0.01$ & $0.00 \pm 0.00 *$ \\
\hline $\operatorname{AST}(\mathrm{U} / \mathrm{l})$ & $147.30 \pm 7.25$ & $161.22 \pm 21.87$ & $133.40 \pm 8.94$ & $138.80 \pm 10.41$ & $133.67 \pm 7.44$ \\
\hline $\operatorname{ALT}(\mathrm{U} / \mathrm{l})$ & $47.90 \pm 3.65$ & $63.22 \pm 8.17$ & $48.00 \pm 3.54$ & $56.20 \pm 8.50$ & $59.22 \pm 5.57$ \\
\hline $\operatorname{ALP}(\mathrm{U} / \mathrm{l})$ & $56.30 \pm 2.19$ & $57.89 \pm 3.13$ & $62.50 \pm 2.77$ & $55.10 \pm 1.54$ & $52.44 \pm 2.44$ \\
\hline
\end{tabular}

Values are expressed as mean \pm S.E.M., $\mathrm{n}=10$

Satellite: a group was treated with oral dose of $1,200 \mathrm{mg} / \mathrm{kg}$ body weight/day for 270 days following by no treatment for 28 days.

* Significantly different from control, $\mathrm{p}<0.05$. 
Sireeratawong et al., Afr J Tradit Complement Altern Med. (2013) 10(2):223-231

Table 4: Effect of $T$. bellerica water extract on organ weights of female and male rats in the chronic toxicity test

\begin{tabular}{|c|c|c|c|c|c|}
\hline \multirow[t]{2}{*}{ Organ } & \multirow[b]{2}{*}{ Control } & \multicolumn{4}{|c|}{ T. bellerica water extract } \\
\hline & & $300 \mathrm{mg} / \mathrm{kg}$ & $600 \mathrm{mg} / \mathrm{kg}$ & $1,200 \mathrm{mg} / \mathrm{kg}$ & Satellite \\
\hline \multicolumn{6}{|l|}{ Female } \\
\hline Brain & $1.95 \pm 0.02$ & $1.94 \pm 0.03$ & $1.83 \pm 0.04 *$ & $1.90 \pm 0.03$ & $1.91 \pm 0.02$ \\
\hline Lung & $1.88 \pm 0.13$ & $1.72 \pm 0.05$ & $1.78 \pm 0.12$ & $1.68 \pm 0.06$ & $1.60 \pm 0.05^{*}$ \\
\hline Heart & $1.24 \pm 0.05$ & $1.31 \pm 0.05$ & $1.17 \pm 0.04$ & $1.25 \pm 0.05$ & $1.32 \pm 0.04$ \\
\hline Liver & $9.55 \pm 0.44$ & $8.79 \pm 0.35$ & $8.48 \pm 0.23^{*}$ & $8.73 \pm 0.31$ & $8.96 \pm 0.41$ \\
\hline Pancreas & $1.45 \pm 0.06$ & $1.38 \pm 0.09$ & $1.40 \pm 0.10$ & $1.60 \pm 0.10$ & $1.66 \pm 0.11$ \\
\hline Spleen & $0.90 \pm 0.04$ & $0.91 \pm 0.03$ & $0.79 \pm 0.03 *$ & $0.86 \pm 0.04$ & $0.91 \pm 0.02$ \\
\hline Adrenal & $0.03 \pm 0.00$ & $0.03 \pm 0.00$ & $0.04 \pm 0.00$ & $0.03 \pm 0.02$ & $0.03 \pm 0.00$ \\
\hline Kidney & $1.29 \pm 0.03$ & $1.27 \pm 0.03$ & $1.16 \pm 0.02 *$ & $1.25 \pm 0.03$ & $1.32 \pm 0.03$ \\
\hline Ovary & $0.07 \pm 0.00$ & $0.08 \pm 0.00$ & $0.09 \pm 0.00$ & $0.06 \pm 0.03$ & $0.07 \pm 0.00$ \\
\hline Uterus & $0.69 \pm 0.08$ & $0.86 \pm 0.09$ & $0.74 \pm 0.06$ & $0.71 \pm 0.06$ & $0.63 \pm 0.04$ \\
\hline \multicolumn{6}{|l|}{ Male } \\
\hline Brain & $2.08 \pm 0.04$ & $1.99 \pm 0.02$ & $1.96 \pm 0.03 *$ & $2.01 \pm 0.04$ & $2.00 \pm 0.03$ \\
\hline Lung & $2.76 \pm 0.29$ & $2.49 \pm 0.12$ & $2.10 \pm 0.11^{*}$ & $2.08 \pm 0.08^{*}$ & $2.41 \pm 0.31$ \\
\hline Heart & $1.77 \pm 0.04$ & $1.61 \pm 0.06^{*}$ & $1.55 \pm 0.05^{*}$ & $1.61 \pm 0.07^{*}$ & $1.65 \pm 0.06$ \\
\hline Liver & $14.65 \pm 0.41$ & $13.67 \pm 0.39$ & $11.95 \pm 0.42 *$ & $13.56 \pm 0.55$ & $15.99 \pm 0.65$ \\
\hline Pancreas & $1.34 \pm 0.10$ & $1.37 \pm 0.10$ & $1.62 \pm 0.10$ & $1.64 \pm 0.13$ & $1.59 \pm 0.10$ \\
\hline Spleen & 1.150 .04 & $1.04 \pm 0.05$ & $1.00 \pm 0.11$ & $0.94 \pm 0.04 *$ & $1.10 \pm 0.05$ \\
\hline Adrenal & $0.03 \pm 0.00$ & $0.04 \pm 0.00$ & $0.03 \pm 0.00$ & $0.04 \pm 0.00$ & $0.04 \pm 0.00$ \\
\hline Kidney & $1.72 \pm 0.04$ & $1.65 \pm 0.03$ & $1.56 \pm 0.04 *$ & $1.64 \pm 0.04$ & $1.86 \pm 0.05 *$ \\
\hline Testis & $1.98 \pm 0.41$ & $2.03 \pm 0.02$ & $1.91 \pm 0.05$ & $2.03 \pm 0.03$ & $2.03 \pm 0.06$ \\
\hline Epididymis & $0.81 \pm 0.02$ & $0.80 \pm 0.03$ & $0.82 \pm 0.02$ & $0.86 \pm 0.03$ & $0.83 \pm 0.01$ \\
\hline
\end{tabular}

Values are expressed as mean \pm S.E.M., $\mathrm{n}=10$.

Satellite: a group was treated with oral dose of $1,200 \mathrm{mg} / \mathrm{kg}$ body weight/day for 270 days following by no treatment for 28 days.

* Significantly different from control, $\mathrm{p}<0.05$. 


\section{Discussion}

The single oral high dose of TB extract $(5,000 \mathrm{mg} / \mathrm{kg})$ in acute toxicity test did not show any toxicity signs or no significant differences in body weight, internal organ weight, and general behaviors in female and male SD rats. Furthermore, gross and pathological examinations of the internal organs revealed no pathological abnormality. The results suggest that the TB extract is virtually not toxic after an acute exposure in rats.

In chronic toxicity study for 270 days, both female and male rats were treated with TB extract at all three doses (300, 600, and $1,200 \mathrm{mg} / \mathrm{kg}$ body weight. All rats at each dosage presented no signs of behavior changes, toxic signs and mortalities.

The female treated groups revealed no significant differences in body weight gain and internal organ weight. In contrast, the body weight gain of male treated groups at all doses was significantly lower than control groups. However, the affected of body weight and body weight gain may result from physiological changes such as decrease, increase food intake, and metabolism. The result from animal health monitoring in the entire period of 270 days showed no sign of morbidity or diseases. Moreover, both female and male rats were healthy as shown by the normal appearance of general behavior, respiratory pattern, cardiovascular signs, motor activities, reflexes, and normal change in skin and fur.

Bone marrow may be one of the target sites for the adverse effects of test substances. The hematological values were thus assessed in order to evaluate any toxic effects on function of bone marrow. White blood cell count was performed in order to evaluate immune system. In the present study, some hematological values in treated groups were significantly different from those of the control group such as red blood cells, hematocrit, MCV, MCHC, lymphocyte, monocyte, and eosinophil, but these values are within the normal ranges. These variations may result from normal variation among animal groups (Inala et al., 2002; Feldman et al., 2000). This finding suggests that the TB extract did not cause hematological or immunological defects.

Blood chemical examination was used to evaluate any toxic effects on liver, kidney and pancreas. In our study, a significant difference of blood chemical values was observed in both female and male rats, but these blood chemical levels remained within the normal range (Angkhasirisap et al., 2002; Barry 1995). These results suggest that TB extract has no effect on liver, kidney and pancreas functions.

Gross and pathological examinations of internal organs were performed to further confirm whether or not the organs or tissues had been damaged (Hayes, 2001). The results showed no macroscopic or microscopic changes in these internal organs or tissues in any treated rats, indicating that this test substance has no toxic effect.

In conclusion, the water extract from the dried fruits of $T$. bellerica given orally to female and male rats did not produce both acute and chronic toxicities. These data confirm that this water extract is safe for the rodent's use. Further study regarding toxicology of this extract should be carried out in non-rodent or human in order to increase the confidence in their safety for the development of pharmaceutical products in the future.

\section{Acknowledgements}

The authors would like to thank the National Research Council of Thailand for financial support.

\section{References}

1. Ahmad, I., Mehmood, Z. and Mohammad, F. (1998). Screening of some Indian medicinal plants for their antimicrobial properties. J. Ethnopharmacol. 62(2): 183 - 193.

2. Angkhasirisap, W., Inala, P., Sirimontaporn, A., Inpunkaew, R., Rungrojejinda, K., Kengkoom, K., Ratanasak, W. and Buripadi Lawson, D. (2002). Blood chemistry profiles of outbred Sprague-Dawley rat in the Facility of National Laboratory Animal Centre. 28th Congress on Science and Technology of Thailand.

3. Bajpai, M., Pande, A., Tewari, S.K. and Prakash, D. (2005). Phenolic contents and antioxidant activity of some food and medicinal plants. Int. J. Food. Sci. Nutr. 56(4): 287 - 291.

4. Barry, S.L. (1995). Animal Clinical Pathology. In: Derelanko MJ, Hollinger MA, editors. CRC Handbook of Toxicology. CRC Press, U.S.A., pp 517 - 537.

5. Department of Medical Sciences, Ministry of Public Health. (2000). Thai Herbal Pharmacopoeia Volume II. Nonthaburi, Thailand.

6. Elizabeth, K.M. (2005). Antimicrobial activity of Terminalia bellerica. Indian J. Clin. Biochem. 20(2): 150 - 153.

7. el-Mekkawy, S., Meselhy, M.R., Kusumoto, I.T., Kadota, S., Hattori, M. and Namba, T. (1995). Inhibitory effects of Egyptian folk medicines on human immunodeficiency virus (HIV) reverse transcriptase. Chem. Pharm. Bull. (Tokyo). 43(4): 641 - 648.

8. Feldman, B.F., Zinkl, J.G., Jain, N.C. and Moor, D.M. (2000). Schalm’s Veterinary Hematology. 5th ed. Lippincott Williams \& Wilkins, Philadelphia.

9. Hayes, A.W. (2001). Principle and method of toxicity: short-term, subchronic, and chronic toxicology studies. $4^{\text {th }}$ ed, Taylor \& Francis, Philadelphia, pp 917 - 955.

10. Inala, P., Sirimontaporn, A., Inpunkaew, R., Rungrojejinda, K., Kengkoom, K., Ratanasak, W. and Buripakdi Lawson, D. (2002). Hematological analysis of outbred Sprague-Dawley rat in the Facility of National Laboratory Animal Centre. 28th Congress on Science and Technology of Thailand.

11. Mokkhasmit, M., Swatdimongkol, K. and Satrawaha, P. (1971). Study on toxicity of Thai medicinal plants. Bull. Dept. Med. Sci. 12: 36 - 65. 
Sireeratawong et al., Afr J Tradit Complement Altern Med. (2013) 10(2):223-231

http://dx.doi.org/10.4314/ajtcam.v10i2.6

12. Organization of Economic Co-operation and Development (OECD). (1981). Test Guideline 452. Chronic Toxicity Studies. In: OECD Guidelines for the testing of chemicals, Organization for Economic Cooperation \& Development, Paris.

13. Organization of Economic Co-operation and Development (OECD). (2001). Test Guideline 420. Acute oral toxicity-fixed dose method. In: OECD Guideline for testing of chemicals, Organization for Economic Cooperation \& Development, Paris.

14. Smitinand, T. (2001). Thai Plant Names Dictionary. Bangkok, Thailand: The forest herbarium, Royal forest department.

15. Thanaporn, S., Jaijoy, K., Thamaree, S., Ingkaninan, K. and Panthong, A. (2006). Acute and subacute toxicity study of the ethanol extract from the fruit of Terminalia bellerica. Mahidol University J. Pharm. Sci. 33(1-4): 23 30.

16. Valsaraj, R., Pushpangadan, P., Smitt, U.W., Adsersen, A., Christensen, S.B., Sittie, A., Nyman, U., Nielsen, C. and Olsen, C.E. (1997). New anti-HIV-1, antimalarial, and antifungal compounds from Terminalia bellerica. J. Nat. Prod. 60(7): 739 - 742.

17. World Health Organization (WHO). (2000). General guidelines for methodologies on research and evaluation of traditional medicine. Switzerland. 